\title{
The Development of BIM Model-based Construction Project Performance Evaluation Mechanism
}

\author{
Yi-Jao Chen ${ }^{1, *}$, Chung-Wei Feng ${ }^{1}$, Kai-Ming Yang ${ }^{2}$ \\ ${ }^{1}$ Department of Information Communication, University of Kang Ning, Taiwan \\ ${ }^{2}$ Department of Civil Engineering, National Cheng Kung University, Taiwan
}

Copyright $(\subset 2015$ by authors, all rights reserved. Authors agree that this article remains permanently open access under the terms of the Creative Commons Attribution License 4.0 International License

\begin{abstract}
In construction industries, performance evaluation is used as a systematic way of judging project performance. However, it is still a daunting task for project managers to accurately and timely record of the current status on the site due to the project's dynamic nature. In addition, there is no effective mechanism available yet to integrate information among all the project participants. In view of this, a construction project performance evaluation mechanism based on BIM model will be proposed in this research. Firstly, a systematic analysis will be conducted to analyze the current process and structure of the evaluation of construction projects. Based on existing IFC/BIM, the current IFC data structure will be extended accordingly and BIM graphic objects will be created to describe project information. Using graphic objects to describe relative project information, they form a reliable resource for project performance evaluation. Finally, the construction project performance evaluation mechanism will be developed to verify the feasibility of the proposed approach.
\end{abstract}

Keyword Building Information Modeling, Construction Management, Project Performance Evaluation, Information Integration

\section{Introduction}

In construction industries, successful project delivery requires the concerted effort of the project team to carry out the various project activities, but it is the project manager who, at the center of the project network, is responsible for orchestrating the whole construction process [1]. The project manager has to maintain the project network and monitor against slippages in cost, time, and quality for the duration of the project [2]. In achieving this, the project manager relies heavily on a reliable performance evaluation mechanism that can provide timely signalling of project problems, whether they are real or potential.

However, traditional performance monitoring is usually carried out by evaluation forms filled by project members at regular intervals. It is often the case that the project manager can only examine the project status several weeks after completion of the data collection process. This type of post-evaluation is inadequate given the rapid progress of most construction projects[3].

Therefore, information processing is perhaps the biggest challenge facing project teams involved in performance evaluation. As a construction project increases in size or complexity, the efficiency and accuracy of information processing between different project participants have a tremendous impact on the successful execution of a construction project. However, there is no effective mechanism available yet to integrate information among all the project participants. In view of this, a construction project performance evaluation mechanism based on BIM model will be proposed in this research. The proposed BIM model incorporates multi-aspects of construction information required for project management and performance evaluation.

In order to present the information of construction activities and specifications in the BIM model, this research starts with analyzing the discrete processes within the building construction. The essential characteristics of building elements are then defined in the property sets of the BIM objects [4]. These graphic objects are then further developed as schedulable objects and utilized to create the project BIM model. The BIM model is also transformed as a database for project management. Using graphic objects to describe relative project information, they form a reliable resource for project performance evaluation. In addition, the construction project performance evaluation mechanism will be developed to verify the feasibility of the proposed approach.

\section{Construction-driven BIM Model}

In construction projects, the management processes generate a great number of data and information of various 
kinds. The management and the communication of these data by the various participants is complex. The proposed construction-driven BIM model is an extension of current building information modeling (BIM). The purpose of construction-driven BIM model is to facilitate the automating acquisition of project data and the sharing process of project information.

BIM is an innovative approach to modeling building information in a $3 \mathrm{D}$ object-based information system. BIM is the process of generating, storing, managing, exchanging, and sharing building information in an interoperable and reusable way. 3D parametric systems facilitate the construction of a virtual digital building that contains an unambiguous geometric description of the building. In addition, a BIM system is a tool that enables users to integrate and reuse building information and domain knowledge throughout the lifecycle of a building [5].

In the development of BIM applications, the Industry Foundation Classes (IFC) product model developed by the International Alliance for Interoperability (IAI) has been widely adopted as a public standard for the representation and transfer of 3D object-based data [6]. Although the model schema of building product is now available, standards in the construction management domain still need to be defined. The current IFC is still incapable of providing sufficient information for construction activities [7].

From a project management perspective, an ideal world would be the one in which an architect and a project planner are able to exchange BIM model data between their applications in a seamless fashion [8]. Thus, for facilitating project performance evaluation, more construction knowledge and project information should be implemented in BIM models to effectively generate the required information. In addition, as a core of information integration for project management, an ideal integrated BIM model would not consist only of the physical elements of a building. The relationships among the building elements and construction activities are also crucial for a construction-driven BIM model.

\section{Project Information Processing}

In order to present the information on construction activities and specifications in the BIM model, this paper analyzes the discrete processes undertaken within building construction. Several facets, such as dimensions, spaces, elements, materials, work sections, management are used to classify the construction information. These attributes are divided in three aspects include containment hierarchy, geometric data, and construction contents, and used to present the essential properties of building elements.

In the containment hierarchy, the BIM model is structured per the IFC BIM standard. The building elements are further classified into physical, spatial, and logical objects in this paper. The physical objects include basic building elements such as slabs, columns, beams, walls, doors, and windows. Uniformat II was the classification system adopted in this study for classifying physical objects and related sitework[9]. Spatial objects include spaces and zones. Generally, a space is bounded by several building elements, and a zone is made up of spaces. This containment hierarchy defines the structure of the BIM model and is useful for integrating and processing project information (Fig.1).

In the geometric aspect, the attributes include the coordinates and dimensions of the building element. With 3D parametric modeling, these geometric attributes are readily available in the $\mathrm{CAD}$ systems. The dimensions of a building element such as width, depth, height, area, and volume, are utilized as a reliable source in quantity take-off for construction estimation.

In construction contents, the work necessary to construct the building elements is described by the specifications of the required work sections. The work items employed in this study are classified and coded according to the hierarchical standard codes established by the Public Construction Commission (PCC) in Taiwan [10]. The PCC coding system was developed with reference to the CSI MasterFormat system [11]. Based on the Master and Extended codes of a work item, the information of the corresponding regulation and the required resources can be obtained from the PCC database. As a result, the information of construction contents is organized into the project-required work presented graphically by the BIM objects (Fig. 2).

Autodesk Revit Architecture was the primarily used tool for BIM modeling in this study. After the creation of the BIM model, all project-required work can be identified based on the collected work items in the BIM objects. The large amount of information described in the BIM model will be exported as a relational database for project planning and management. 


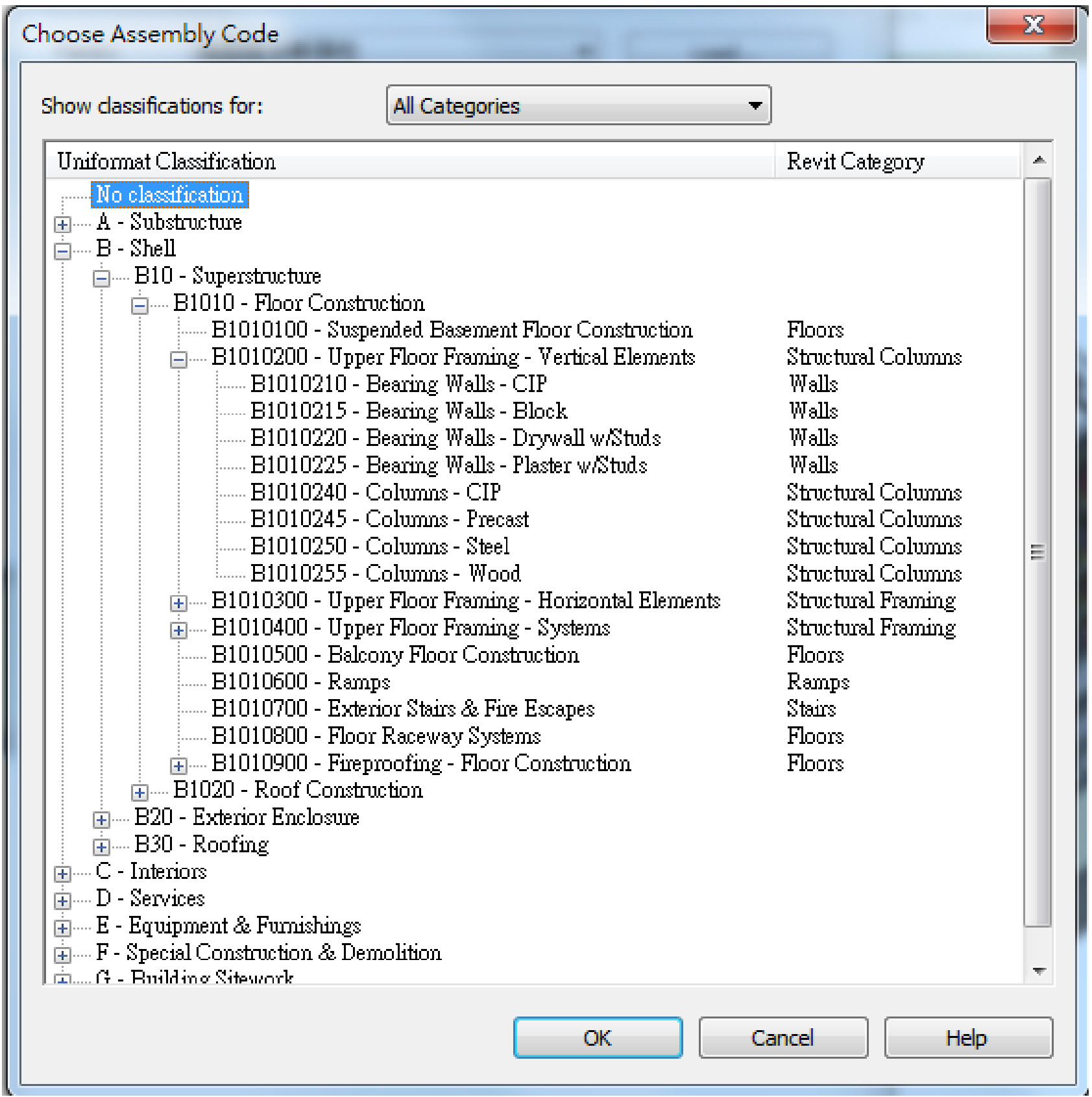

Figure 1. Uniformat II classification system. 


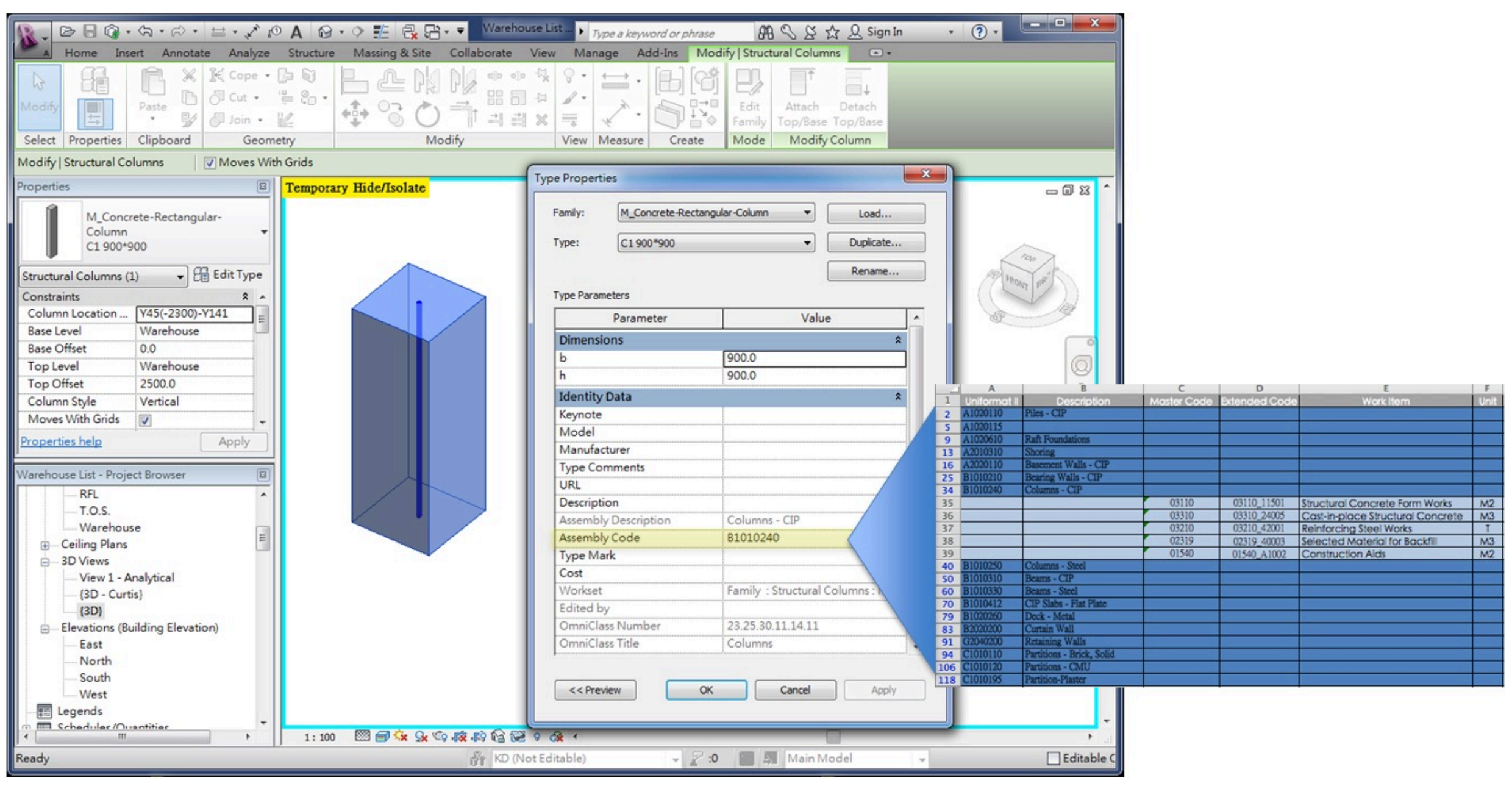

Figure 2. The project-required work presented graphically by the BIM objects. 


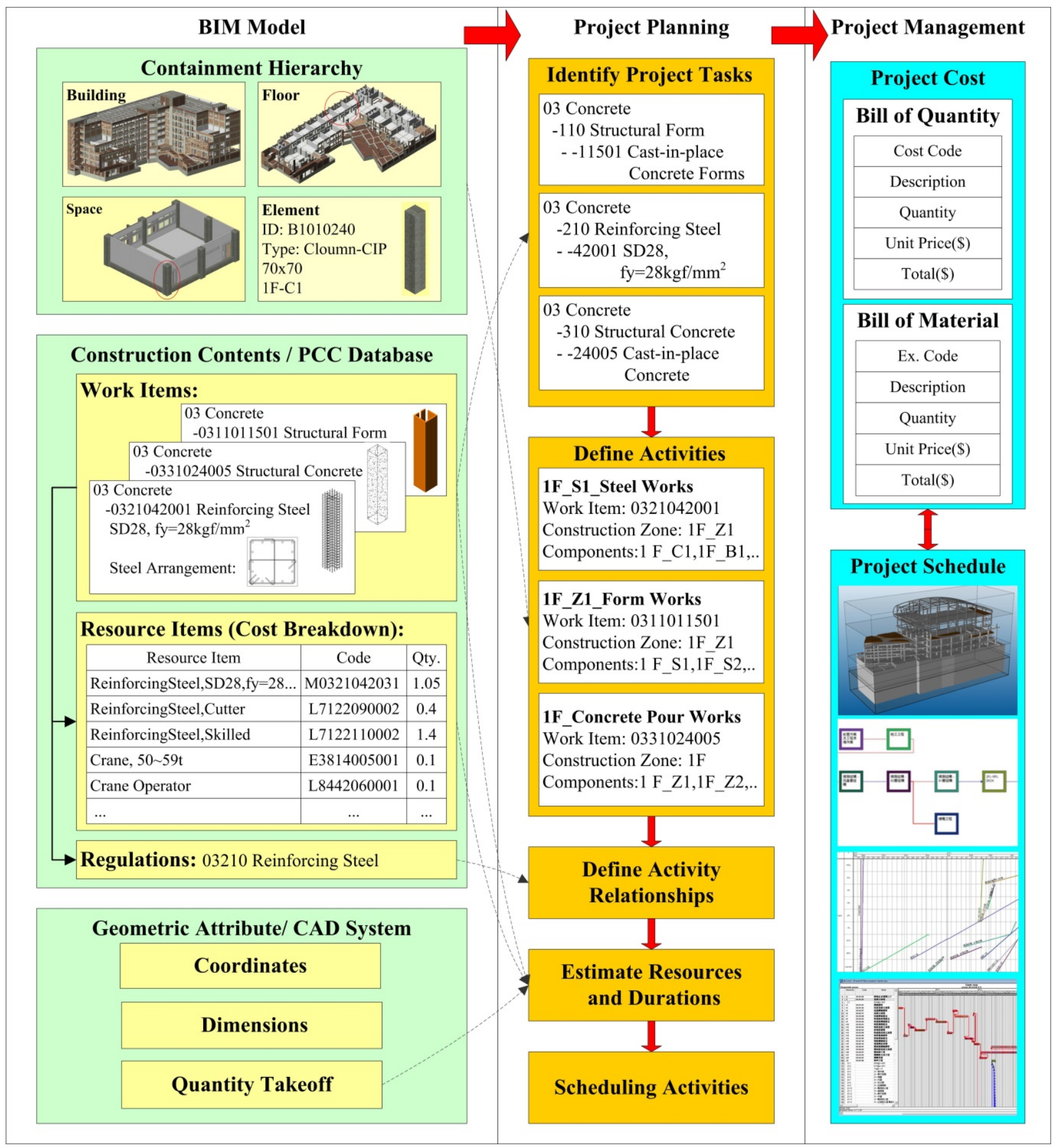

Figure 3. BIM-based project planning and management process 


\section{Project Planning and Management}

The planning process involves the identification of project tasks, the definition of construction activities, the estimation of required resources and durations for individual activities, and the identification of any interactions among the different activities. This research considers the functional requirements for time-cost integrated planning in the development of the BIM model. Vico Office tools [12] were used in the study for cost estimation, Line of Balance construction planning, and construction management. Figure 3 further illustrates the applications of the BIM model in project planning in this research. As seen in the diagram, the BIM model-based planning process can be described as follows.

The initial step in the planning process is to identify the various project tasks that must be accomplished. These project tasks represent the necessary framework to permit scheduling of construction activities, along with the estimating of resources and costs required by the project. Since most complex projects involve thousands of individual project tasks, their identification can be a laborious and tedious process, yet it is required to generate the necessary information for the application of formal planning procedures.

In this research, the BIM model facilitates the process of identifying project tasks by the coded work items. All project-required tasks are identified on the basis of the collected work items described in the BIM objects. For example, the tasks involved in the construction of the structure elements (B1010240 Columns-CIP) may be identified by coded work items such as "03110_11501 Structural Concrete Form Works," “03210_42001 Reinforcing Steel Works," and "03310_24005 Cast-in-place Structural Concrete." The PCC coding system provides a numbering system to replace verbal descriptions of project tasks. With this common coding system, various parties involved in a project can access the project related data with consistency.

The second step in the planning process is to break down the project-required tasks into activities. The set of activities defined for a project should be comprehensive so that all necessary project tasks are included in one or more activities. Descriptions of activities explain the scope and location of the required work; they should be as complete and accurate as possible to assist project managers on project planning. Therefore, at the most detailed level, this research utilizes the BIM objects to define the construction activities based on the building elements. As shown in Fig. 3, construction of the 1F-C1 RC column involves several activities such as placing steel reinforcement, erecting formwork, and pouring concrete. The detailed descriptions of these activities are derived from the attributes of the $1 \mathrm{~F}-\mathrm{C} 1$ element. In addition, according to the containment hierarchy of the BIM model, the element-based activities could be combined into aggregate or "super" activities such as "1F_Space1_Steel Works," "1F_Zone1_Form Works," and "1F_Concrete Pour
Works." The containment hierarchy facilitates the defining of project activities in a standard format for cost estimating, project scheduling, and project control. This hierarchical structure also provides a common, ordered framework for summarizing activity information. Once the activities have been defined, the relationships among them can be specified.

In construction planning, one of the most important steps is the estimation of the resources and time required to complete each activity. In this research, the process of conducting the estimate begins with a detailed and accurate quantity take-off performed on each BIM object. For instance, the amount of concrete pour work required for the 1F-C1 RC column is calculated according to the specified dimensions in geometric attributes. The amount of the pre-defined activity (e.g., 1F_Space1_Concrete Pour Works) is determined by aggregating the quantities of the associated BIM objects. Historical production and costs data from the PCC database are then used to estimate the duration and amount of resources required for each activity. The activity durations are further used to calculate the start/finish times of each activity on the basis of the network diagram. In addition, the estimation of various project costs is performed simultaneously in this process. Finally, the construction-driven BIM model is transformed as a database for project management. The results of the estimate will be recorded on the standard sheets of a Bill of Quantity (BOQ) and Bill of Material (BOM). Moreover, the construction activities with associated resources and costs are scheduled in a bar chart of time frame.

\section{Evaluation Mechanism}

Time and cost are two critical factors determining the success of a construction project [13]. Time and cost are used as key performance parameters in this research. Project cost performance is used to show how well the project adheres to the agreed budget. It is important because resources are often limited and cost overruns are to be avoided. In addition, monitoring project time is one of the many challenges for the project manager. Time monitoring seeks to assess how well the project adheres to the planned schedule over a period of time.

As a core information repository, the construction-driven BIM model consists of the BIM objects ensures the consistency and reliability of project information processing. Since the BIM objects associate each work item with the resources it required and its associated costs. The resulting schedule is integrated with project costs, which makes it possible for planners to easily examine relevant resources and costs of a specified time period and provides information concerning the detailed operations throughout the construction process.

In project performance evaluation, the data obtained from project plan and construction records, such as budgeted cost, actual cost, scheduled completion, and actual completion will be used in the Earned Value (EV) analysis. Earned 
Value $(\mathrm{EV})$ is a project management technique that measures project progress in an objective manner, and provides an early warning of performance issues, if any [14]. EV measures project performance and progress by an integrated management of three most important elements in a project, namely cost, schedule and scope. In summary, EV provides indices for cost and time performances, and for project completion estimation. By definition, EV of an activity is a measure of completed work, and represents the budgeted cost of work performed [15]. Generally speaking, EV indicates how efficiently the project team utilizes the project resources, and is measured as what has been obtained and what was going to be obtained. Two widely used indices in evaluating project progress are Schedule Performance Index (SPI) and Cost Performance Index (CPI). Apart from these indices, several estimations are of interest, like completion cost and completion time of a project. SPI is a conformance measure of actual progress to schedule. SPI is measured as the ratio of EV to Planned Value (PV), that is

$$
\mathrm{SPI}=\mathrm{EV} / \mathrm{PV}
$$

where PV, known also as the Budgeted Cost of Work Scheduled (BCWS), is planned to be used during the project.

CPI is a measure of budgetary conformance of actual cost of work performed, and is the most useful index indicating the cumulative cost efficiency of a project. CPI is the ratio of EV to Actual Cost (AC), that is

$$
\mathrm{CPI}=\mathrm{EV} / \mathrm{AC}
$$

where AC, known also as Actual Cost of Work Performed (ACWP), is an indication of the resources that have been used to achieve the actual work performed.

The monitoring scheme of EV indices of the case study is shown as Fig. 4, where project cost and schedule performances were monitored over a 48 -week period. The EV indices graph were generated by MS Excel. The construction-driven BIM model is capable of generating daily field records for tracking the construction work. The information includes the completion of work items, resource consumption, and cost. The cost and schedule variances assist in evaluating and controlling project risk by measuring progress in monetary terms.

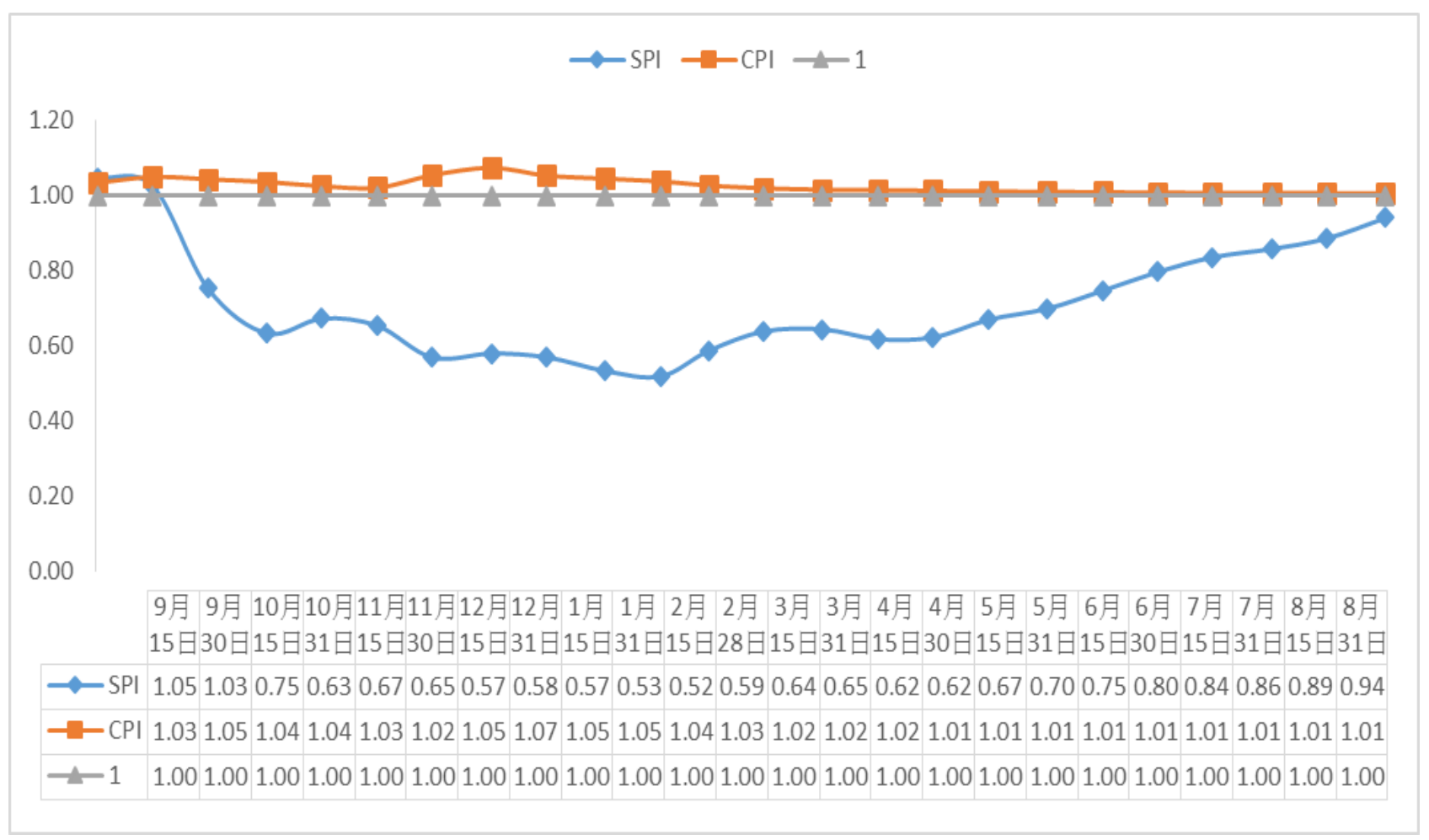

Figure 4. Monitoring scheme of EV indices. 


\section{Conclusions}

This paper presents a BIM model-based project performance evaluation method that employs BIM objects to generate information required for project management. As a core information repository, the BIM model consists of the BIM objects ensures the consistency and reliability of project information processing. From the findings of the case study, this consistent project information model, with associated data regarding functional, material and product information, has the potential to significantly reduce overhead efforts, reduce errors, and improve project performance. Since the BIM objects associate each work item with the resources it required and its associated costs. The resulting schedule is integrated with project costs, which makes it possible for planners to easily examine relevant resources and costs of a specified time period and provides information concerning the detailed operations throughout the construction process. However, the proposed BIM-based project performance evaluation mechanism does have the limitations. This research considered Time and Cost as key performance parameters. In the future research, the parameters of Quality, Safety and Environment will be demonstrated in the evaluation mechanism to develop a comprehensive project performance evaluation system.

\section{Acknowledgements}

This work was supported by the Ministry of Science and Technology, Taiwan under Grant MOST103-2221-E-426-0 01 .

\section{REFERENCES}

[1] Walker, A. (2002). Project Management in Construction, 4th ed., Blackwell, Oxford.

[2] Blackburn, S. (2002). The project manager and the project-network. International Journal of Project Management, 20, 199-204.

[3] Cheung, S.O., Suen, H.C.H. and Cheung, K.K.W. (2004). PPMS: a web-based construction project performance monitoring system. Automation in Construction, 13(3), 361-376.

[4] Feng, C.W., Chen, Y.J. (2008). Applying MD Cad Model to Streamline Information Transformation for Construction Project Planning, Proceedings of the 2008 Architectural Engineering National Conference- AEI 2008: Building Integration Solutions, Denver, CO.

[5] Hartmann, T., Meerveld, H., Vossebeld, N., and Adriaanse A. (2012). Aligning building information model tools and construction management methods. Automation in Construction, 22, 605-613.

[6] IFC Model. Industrial Foundation Classes, International Alliance for Interoperability,

http://www.buildingsmart-tech.org/, (last accessed March 2014).

[7] Fu, C., Aouad, G., Lee, A., Mashall-Ponting, A., and Wu, S. (2006). Ifc Model Viewer to Support Nd Model Application. Automation in Construction, 15(2), 178-185.

[8] Chen, S.M., Griffis, F.H., Chen, P.H., and Chang, L.M. (2013), A framework for an automated and integrated project scheduling and management system. Automation in Construction, 35, 89-110.

[9] Charette, R.P., Marshall, H.E. (1999). UNIFORMAT II elemental classification for building specifications, cost estimating, and cost analysis, NIST U.S. Department of Commerce Technology Administration National Institute of Standards and Technology NISTIR 6389.

[10] PCC Standard Codes. The Public Construction Master Codes and the Public Construction Extended Codes, Public Construction Commission in Taiwan, http://www.pcc.gov.tw, (last accessed March 2014).

[11] Masterformat. (1996). Construction Specifications Institute, Alexandria, Va.

[12] Vico Software. Virtual construction, http://www.vicosoftware.com/, (last accessed March 2014).

[13] Feng, C.W., Chen, Y.J., and Huang, J.R. (2010). Using the MD CAD Model to Develop the Time-Cost Integrated Schedule for Construction Projects. Automation in Construction, 19(3), 347-356.

[14] PMI. (2004). Project Management Body of Knowledge (PMBOK®), 3rd ed. Project Management Institute.

[15] PMI. (2005). Practice Standard for Earned Value Management. Project Management Institute. 